\title{
Factors affecting management changes on farms participating in a Johne's disease control program
}

\author{
R. Wolf, ${ }^{1}$ H. W. Barkema, J. De Buck, and K. Orsel \\ Department of Production Animal Health, Faculty of Veterinary Medicine, University of Calgary, Calgary, Alberta, Canada T2N 4N1
}

\begin{abstract}
Modern Johne's disease programs aim to control Mycobacterium avium ssp. paratuberculosis (MAP) infection through implementation of management practices that reduce the probability of MAP introduction and within-herd transmission on dairy farms. Success of these programs depends on whether weaknesses in management are corrected through implementation of management improvements. The objectives of this study were, therefore, to (1) assess whether scores in risk-assessment (RA) questions predicted suggestions for management changes for the upcoming year; and (2) determine factors as assessed in an RA that motivated producers to make management improvements and assess whether management improvements were influenced by previously received test results. The RA determining on-farm management related to MAP introduction and transmission were conducted annually by herd veterinarians on 370 dairy farms participating in the Alberta Johne's Disease Initiative. A maximum of 3 management changes that the farmer and the veterinarian agreed upon were recorded in a management plan. The MAP infection status of the herds was assessed through culture of 6 environmental samples. Whereas a management change was proposed for only $4 \%$ of questions with scores 1 or 2 (low risk), a change was proposed for $19 \%$ of questions with scores $>2$ $[$ high risk; odds ratio $(\mathrm{OR})=11.4]$. Improvement in RA question scores was more likely between the first and second annual RA than between the second and third RA (OR $=1.6)$. Farms with $>3$ culture-positive environmental samples collected in the previous year were more likely to improve their management than environmental sample culture-negative farms ( $\mathrm{OR}=$ 1.3). In conclusion, proposed management changes were oriented toward previously identified weaknesses in management practices, suggesting that the RA was properly used to design targeted management suggestions. Furthermore, improvements in management were
\end{abstract}

Received March 23, 2015.

Accepted July 17, 2015.

${ }^{1}$ Corresponding author: robert.wolf@stmk.gv.at not randomly distributed among farms participating in the control program. Instead, knowledge of MAP infection status of a herd, suggestions for management improvements, and duration of participation all influenced implementation of management improvements. Key words: paratuberculosis, control, management

\section{INTRODUCTION}

Mycobacterium avium ssp. paratuberculosis (MAP) is present on dairy farms worldwide (Barkema et al., 2010), causes economic losses to the industry (Wolf et al., 2014b), and is potentially associated with Crohn's disease in humans (Atreya et al., 2014). After in utero or fecal-oral infection, cattle go through an extended incubation period that can ultimately result in development of Johne's disease, a noncurable enteritis (Sweeney, 2011). During incubation, infected cattle frequently remain undetected because antibody production and bacterial shedding occur only intermittently (Mortier et al., 2014a,b), and available tests lack accuracy (Nielsen and Toft, 2008), thereby reducing the effectiveness of testing and culling for successful eradication of MAP on cattle farms (Whitlock and Buergelt, 1996; Garry, 2011). As a consequence, most MAP-control programs are not solely based on testing and culling, but encourage implementation of best management practices to prevent MAP introduction and transmission between infectious and susceptible cattle (McKenna et al., 2006). These MAP-control programs can, however, only be effective if farmers make the appropriate management improvements.

The first step toward successful MAP control using best management practices is to identify weaknesses in management and propose changes (Garry, 2011). Weaknesses in management can be identified through the use of a MAP-specific risk assessment, which is completed by farmers and herd veterinarians working in collaboration. Thereafter, identified weaknesses can be addressed by proposed management improvements (USDA, 2003). However, risk assessment as a tool only makes sense if proposed management changes are actually oriented toward deficiencies in management practices. 
The second step, after identifying weaknesses in management, is to improve on-farm management. In 2 US studies, farms generally improved their management during participation in a MAP-control program (Raizman et al., 2006; Wells et al., 2008). Nevertheless, whereas the majority of Ontario dairy farms significantly improved their management, on $20 \%$ of the farms, management significantly worsened (Sorge et al., 2011). Decisions regarding management changes are complex and, among others, motivated by expected increases in profit (Edwards-Jones, 2006). Therefore, farmers that know about the presence of a pathogen might be more likely to invest in its control. Furthermore, owners of large herds are regarded as more progressive than owners of small herds (Bergevoet et al., 2004; Sayers et al., 2013), and farms with high risk assessment (RA) scores (bad management) make more management improvements (Sorge et al., 2011). Therefore, the objectives of our study were to (1) assess whether scores in RA questions predicted suggestions for management changes for the upcoming year; and (2) determine factors as assessed in an RA that motivated producers to make management improvements and assess whether management improvements were influenced by previously received test results.

\section{MATERIALS AND METHODS}

\section{Data Collection}

Participants in this longitudinal study consisted of the 370 dairy farms (63\% of dairy farms in Alberta, Canada) that voluntarily participated in the Alberta Johne's Disease Initiative (AJDI), a managementbased MAP-control program (Wolf et al., 2014a). Data were collected between November 2010 and April 2014 (farmers could join and leave the program at any given time). Herds were visited annually by their herd veterinarians, who were trained (half-day workshop at the University of Calgary) regarding the importance of MAP control, the link between MAP and Crohn's disease, effective management strategies to control MAP, and the correct way of conducting AJDI procedures. During each visit, veterinarians conducted an RA that identified risk factors for MAP infection on the farm (Appendix, Table A1). The first 4 RA questions dealt with herd characteristics (e.g., herd size and housing), whereas questions 5 to 34 were actual risk factors and management practices as related to MAP introduction and transmission and were based on previous suggestions for RA design (USDA, 2003). Questions had categorical scores (3-5 categories); a higher score was associated with an increased risk. After identifying high-risk areas, veterinarians and farmers decided on a maximum of 3 proposed management improvements, which were recorded in a management plan (MP). Proposal of $<3$ management improvements was possible if farmers and veterinarians did not see the need for further management improvements. To assess the herds MAP-infection status, 6 environmental samples (ES) were collected during the herd visit (Wolf et al., 2014a) and processed within 1 wk after collection using a standardized liquid culture protocol with subsequent PCR confirmation conducted on all samples (Forde et al., 2013; Wolf et al., 2014a).

\section{Statistical Analyses}

Data were entered in Microsoft Access (Microsoft Corporation, Redmond, WA, 2007), and management suggestions were linked to associated RA questions. In case of implementation of the suggested change, the scores for these questions were expected to decrease. Data analysis was conducted using STATA 11 (Statacorp, College Station, TX), and statistical significance was defined as $P<0.05$.

\section{Proposed Management Changes}

The number of suggestions in the MP among farms in various years of AJDI participation was compared using a chi-squared test on contingency tables. Proportions of assigned question categories (cattle introductions, visitor access, calf liquid diet, young stock housing, calving pen, lactating and dry cow pens, feeding hygiene and equipment use, and management of likely infected cattle) between veterinarians were also compared using a chi-squared test. Furthermore, proportions of management suggestions made for the different question categories were illustrated in a stacked bar graph, using data from the 9 veterinarians with the highest number of conducted RA. Multilevel logistic regression on question level was used to identify predictors for proposed management changes. The outcome was whether or not $($ yes $=1$, no $=0)$ an improvement related to a specific question in the RA was proposed in the MP. Predictors were (1) the specific question score in the RA $(1,2$, 3,4 , and 5) and (2) the assigned question category ( $\mathrm{n}=9$; categories as described above). The analysis was adjusted for clustering in the data set by including veterinarian, farm, and year of participation as random effects, resulting in a 4-level logistic regression model (Dohoo et al., 2003).

\section{Actual Management Changes}

Multilevel logistic regression was also used to identify predictors for actual changes in individual management 
practices. The outcome was management improvement, defined as score reduction in a specific question did or did not occur between 2 consecutive RA. Predictors were (1) whether or not a question-related management improvement was included in the previous MP; (2) assigned question category (categories as described above); (3) year of participation (management improvements in the second, third and fourth year); (4) mean RA score in the previous year (first, second, third, and fourth quartile of mean RA scores in the data set); (5) herd size (<100, 100-199, >199 cows); and (6) number of positive ES in the previous year $(0,1-3,>3)$. The analysis was adjusted for the score in the specific question during the previous year $(0=$ score 1 and $2,1=$ score $>2$ ). Veterinarian and farm were included in the model as random effects, resulting in a 3-level logistic regression model.

In both models (proposed and actual change), backward selection procedures were used for variable selection, and coefficient changes $>20 \%$ were considered as evidence of confounding. The reported odds ratios (OR) were cluster-specific (Dohoo et al., 2009). Population-averaged OR were not reported because preliminary analysis revealed that the cluster-specific OR were very similar to the population-averaged OR $(<1 \%$ difference). The latent variable approach was used to estimate intraclass correlation coefficients as a measure for the magnitude of clustering by veterinarian, farm, and year of participation (Vigre et al., 2004).

\section{RESULTS}

A total of 709 RA and related MP conducted by 55 veterinary practitioners were received. A total of 137 farms submitted 1 RA, 134 submitted 2 RA, 92 submitted 3 RA, and 7 farms submitted 4 RA. Mean herd size was 139 adult cows, ranging from 40 to 680 cows, with 87,6 , and $7 \%$ of farms that housed cows in freestalls, loose housing, or tiestalls, respectively. Of the 709 RA, 4 had missing observations for some questions because some age groups were housed off-site. These RA were only included in the analysis for questions with available data.

\section{Proposed Management Changes}

Farmers and veterinarians agreed upon a total of 1,598 proposed management changes in the MP (Table 1). Fourteen MP (from 14 farms) did not include any proposed management changes and were excluded from the analysis. The number of proposed management changes decreased with increasing year of a farm's AJDI participation from a mean of $2.38,2.14,2.01$, and 1.86 suggestions per farm in yr 1,2, 3, and 4, respectively $(P<0.01)$. In 8 cases, the proposed management changes could not be identified due to poor handwriting and were excluded from further analysis. The most frequently proposed changes were to increase the number of calving pens $(\mathrm{n}=135 ; 8 \%$ of all proposed management changes), to separate calves from cows soon after birth $(\mathrm{n}=128 ; 8 \%)$, and to avoid spreading manure on pastures grazed the same year $(\mathrm{n}=110$; $7 \%$; Table 1). However, the categories of proposed management improvements that veterinary practitioners proposed differed considerably among the practitioners $(P<0.01$, Figure 1). In total, 8 suggestions were, if implemented, not associated with a decrease in score in any of the RA questions because the RA did not include questions on the particular subject (e.g., not to use milk from test-positive cows to feed calves did not result in a score change for the questions on calf liquid diet because testing of cows was not part of the AJDI program). These suggestions were deleted from further analysis.

Whereas a management change was proposed for 480 of 13,185 questions (4\%) with score 1 and 2 (lowest scores), a change was proposed for 1,711 of 8,807 questions $(19 \%)$ with scores $>2$ (highest scores). In the final logistic regression model, questions with score 4 (high risk) had 11.4 times the odds to result in an agreedupon management change than questions with a score of 1 (low risk; $P<0.001$; Table 2). The odds for a management change to be included in the MP differed among sections in the RA, with questions regarding calf diet having the highest odds for proposed management changes $(P<0.001)$. The low proportions of variance explained by veterinarians and farmers indicated that the associations described in the model were similar across different farms.

\section{Actual Management Changes}

The total (sum) RA score between the first and the last RA improved on $76 \%$ (95\% CI: $70-81 \%$ ) of participating farms (Figure 2). Farms most frequently reduced their scores (risk decrease) in questions around calving pen hygiene (Q23; Appendix, Table A1; 25\% of risk assessments), purchase rates (Q7;24\%), and use of feeding equipment to remove manure and manure contamination on pasture and crop land (Q19, Q30, Q33; 23-25\% dependent on the group of animals; Table 3). Whereas the score of $19 \%$ of the questions improved between 2 consecutive RA on farms with 0 MAP-positive $\mathrm{ES}$, on farms with $>3$ MAP-positive ES the score of $21 \%$ of the questions improved between 2 RA (Table 4). In the final logistic regression model, farms with $>3$ positive ES during the previous year had 1.3 times higher odds for improvement in the score of a question 
Table 1. Percentages of farms with high scores (above category 2 of mainly 4 categories; indicates a high risk) in risk-assessment questions during the first year of participation in the Alberta Johne's Disease Initiative, and frequencies of proposed management changes recorded in the accompanying management plans $(\mathrm{n}=370$ farms $)$

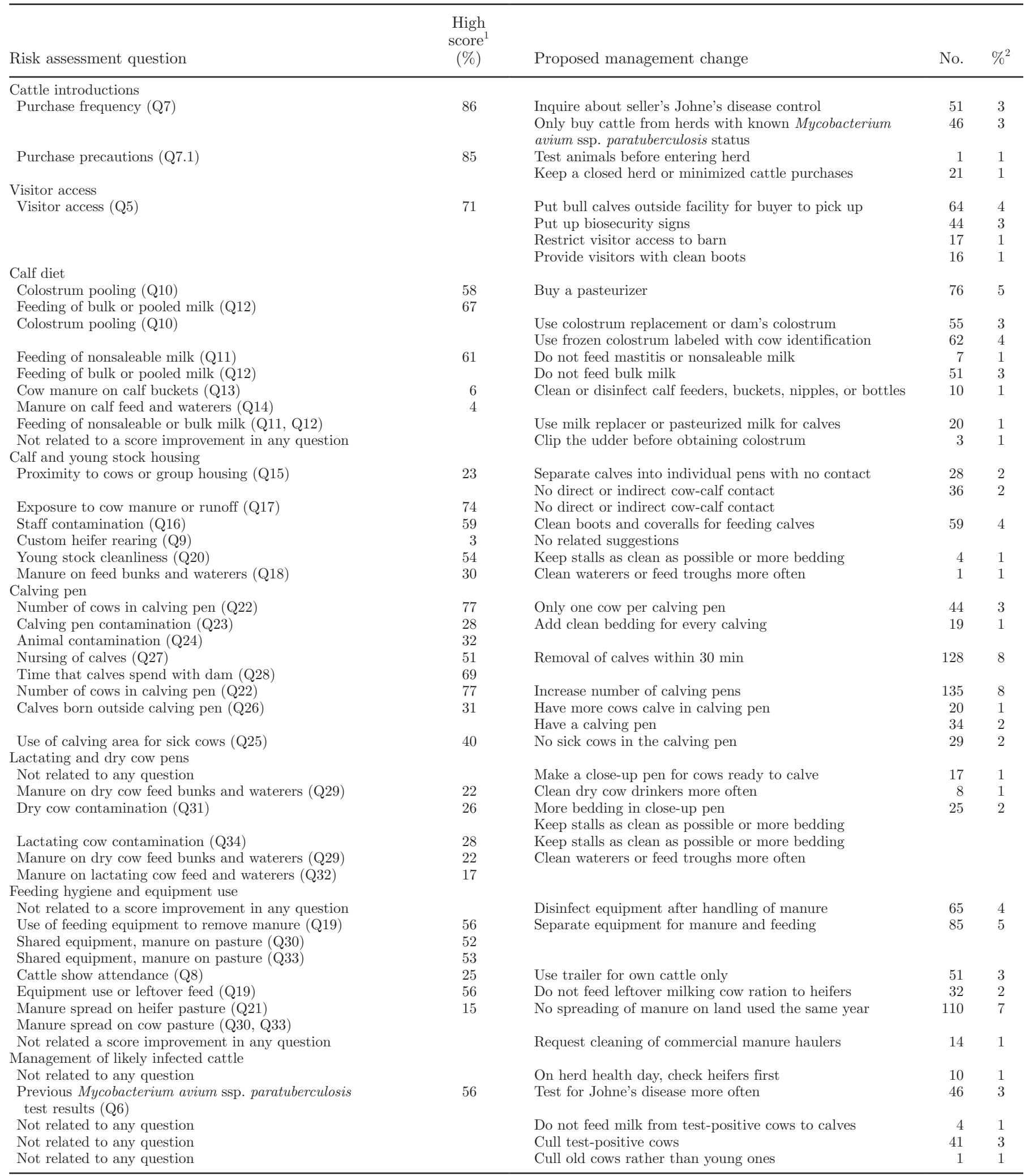

${ }^{1}$ Percentage of farms that had a score $\geq 3$ for the specified question in the first risk assessment.

${ }^{2}$ Percentage of management suggestions among all suggestions. 


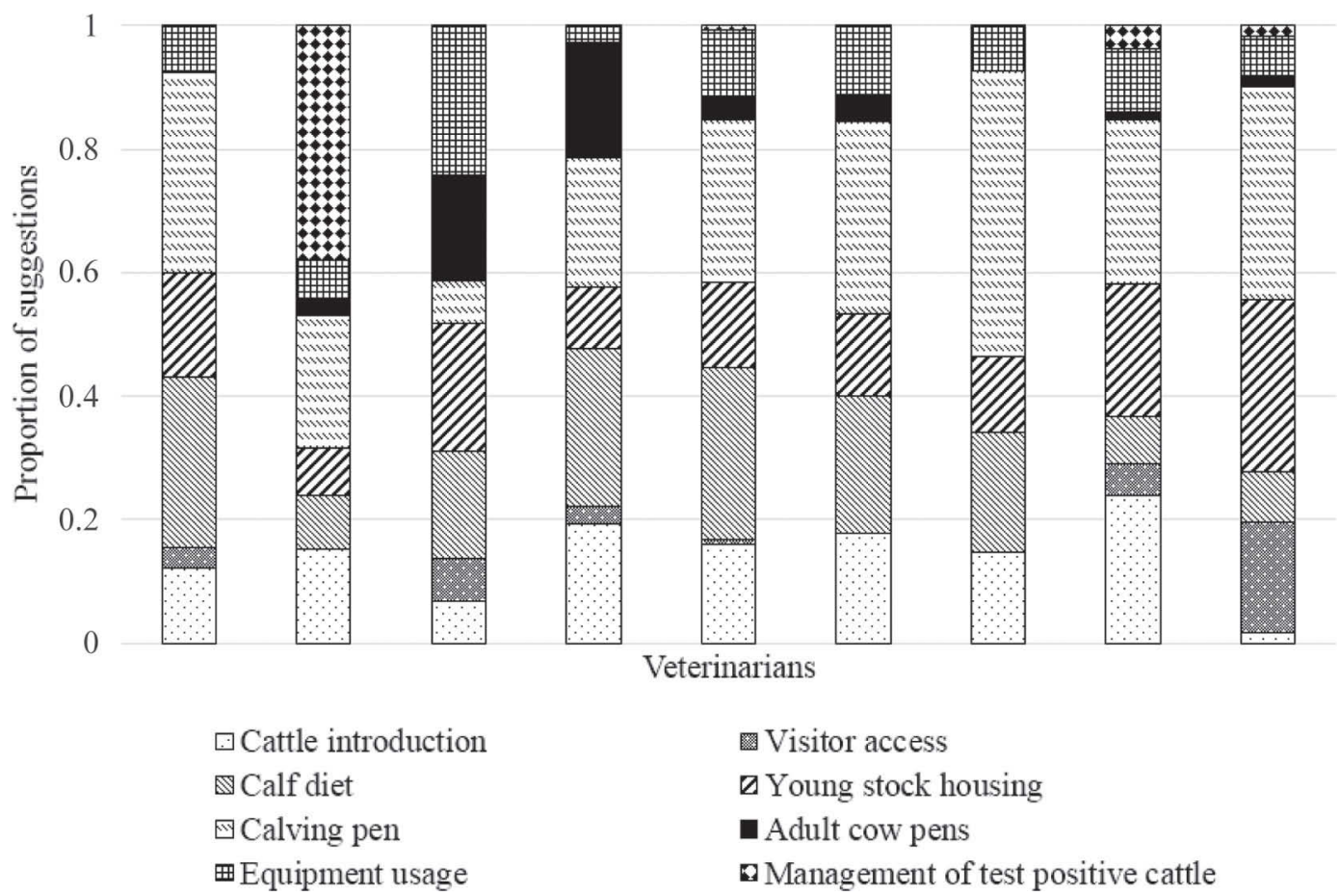

Figure 1. Proportions of proposed management improvements in different management categories suggested by a subset of 9 example veterinarians, each of whom conducted at least 30 Alberta Johne's Disease Initiative risk assessments and management plans.

compared with ES-negative farms $(P=0.02$; Table 5). A question with a proposed management change had 1.32 times the odds to actually improve in score than a question where no change was proposed $(P=0.001)$. The odds for improving the score of a question was $1 / 0.63=1.59$ times higher after the first RA than after

Table 2. Final multilevel logistic regression model for proposing a change in management for a specific question in the Alberta Johne's Disease Initiative risk assessment

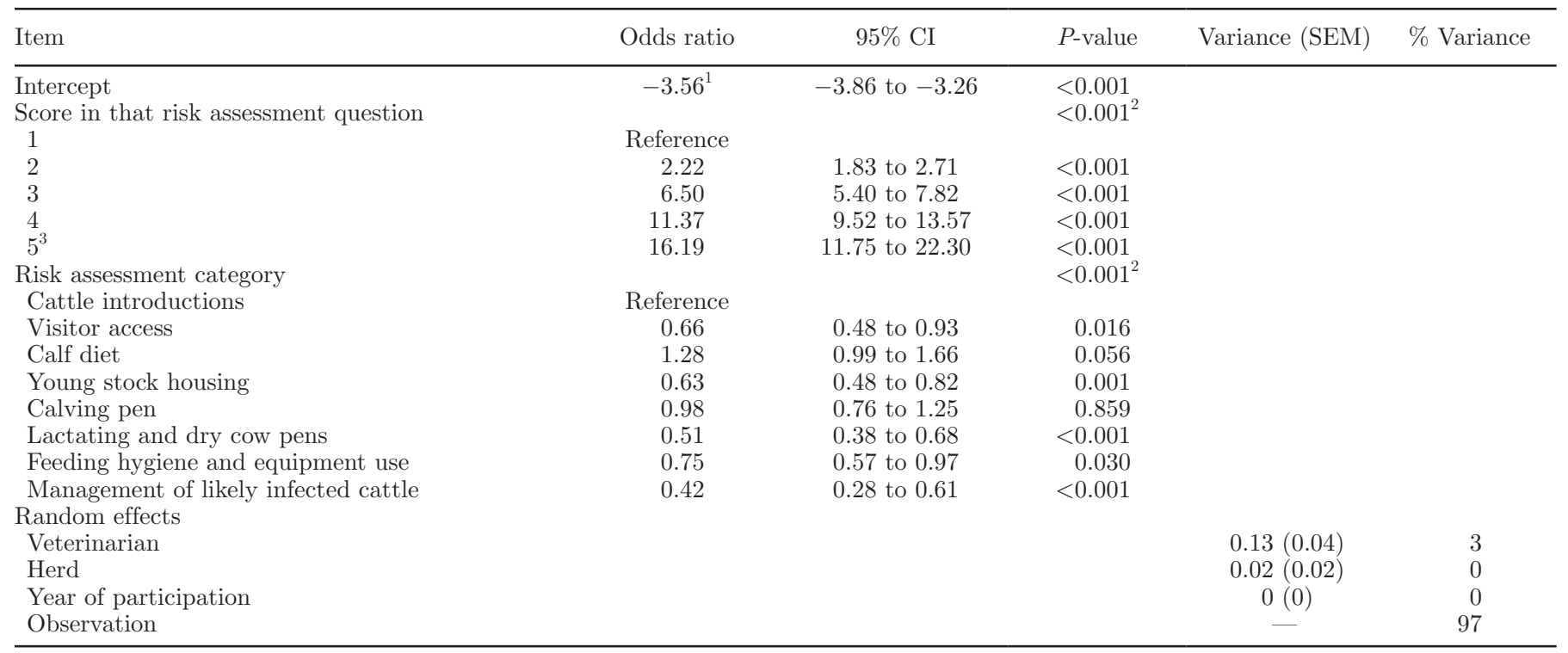

${ }^{1}$ Variable describes the log odds for proposed management change in the baseline group.

${ }^{2}$ Overall Wald $P$-value for the independent variable.

${ }^{3}$ Only possible in 2 questions (Q7 and Q7.1 in Appendix, Table A1). 


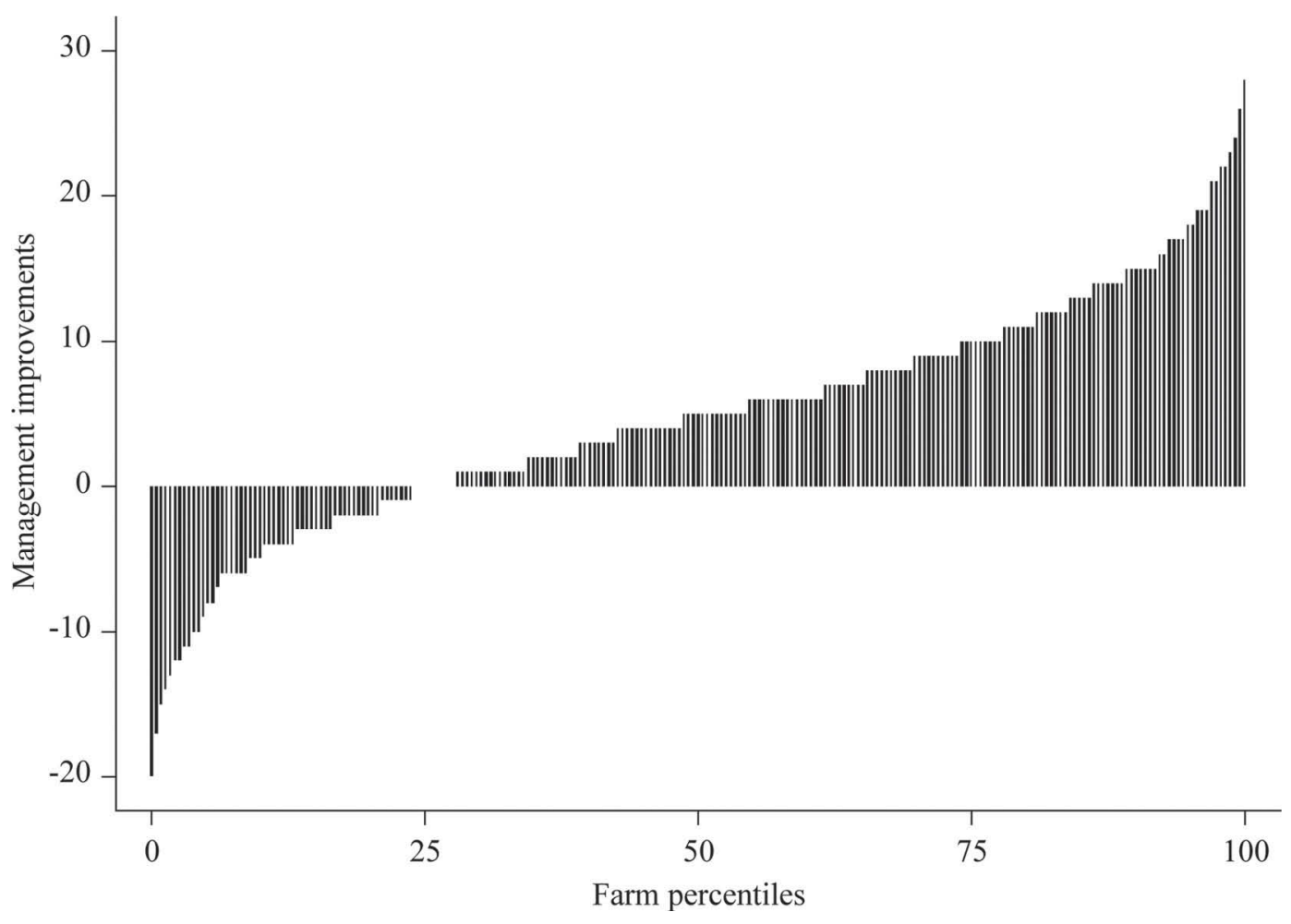

Figure 2. Changes in total (sum) risk assessment (RA) scores between the first and the last RA conducted at 233 farms participating at least $2 \mathrm{yr}$ in the Alberta Johne's Disease Initiative (y-axis = total RA score in first RA - total RA score in last RA; $\mathrm{x}$-axis = farm percentiles; $370=100 \%)$.

the second RA $(P<0.001)$. Improvements in question scores varied between RA categories $(P<0.001)$, with questions regarding cattle introductions least often improving in score.

\section{DISCUSSION}

Identification in the RA of management practices linked to a high risk of introduction or transmission of MAP resulted in proposed management improvements, suggesting that the RA was used properly to draw attention to weaknesses in management, as communicated during AJDI veterinarian workshops. Questions linked to a proposed management change were more likely to actually improve in score in the subsequent year. Furthermore, ES-positive farms were more likely to make management improvements. However, the probability for management improvements decreased with increasing years of participation. Clustering within veterinarians and farms was low, suggesting that described associations were similar among participating farms.

As reported in other MAP-control programs, most farms improved their total RA scores during participation (Raizman et al., 2006; Wells et al., 2008; Sorge et al., 2011). The effect of previously received test results was in agreement with Sorge et al. (2011), who reported more frequent management improvements in herds with MAP ELISA-positive cows compared with herds with MAP ELISA-negative cows (Sorge et al., 2011). A similar relationship was also observed for crop farmers, with those that perceived higher losses caused by a specific pest being more likely to implement a new spraying technique than those that perceived lower losses (Mueller and Jansen, 1988). Positive test results made farmers aware of the presence of MAP in their herd and the associated economic losses. These test-positive farms can expect a higher net benefit from implementation of new management practices than test-negative farms, as higher production through increased health outweighs the costs for management changes (Wolf et al., 2014b). However, motivation for management improvements may be decreased in test-negative, and perhaps false-negative, herds, which could result in increased probabilities for MAP introduction into uninfected herds and increased within-herd transmission in false-negative herds.

Rates of management improvements differed among categories of questions in the RA, similar to Sorge et al. (2011). However, a much stronger driver for proposal of management improvements was the RA score for 
the particular question. This suggests that the RA was properly used to draw attention to observed weaknesses in management on that particular farm.

Implementation of management improvements and number of suggestions made decreased with duration of participation in the AJDI, confirming results of a study reporting similar differences in total RA scores between yr 1 and 2 and yr 1 and 4 (Wells et al., 2008). It is unlikely that 2 or 3 yr of AJDI participation resulted in perfect management. Therefore, farmers and veterinarians likely exhausted cheap and easy to implement options for management improvements. Making changes in RA design over the years, either through focusing on different areas on a farm or adding an additional disease to the program, may increase the motivation to make additional management improvement.
The total RA score was previously identified as a predictor for a reduction in RA scores (Sorge et al., 2011). This is in contrast to results of our study, where the question score in the previous year was identified as a predictor for management improvements and the total RA score did not affect management improvements. This suggests that herds with bad management in general were not more likely to implement management improvements.

In regards to proposed management improvements, results of the present study were similar to results of another study because changes in calf-feeding regimen and calving pen management were frequently proposed in both studies (Pieper et al., 2015). However, whereas purchase of pasteurizers was frequently proposed in the present study, reducing cattle purchase was a focus

Table 3. Question-specific changes in risk assessment (RA) scores on 233 farms participating in the Alberta Johne's Disease Initiative for at least $2 \mathrm{yr}$

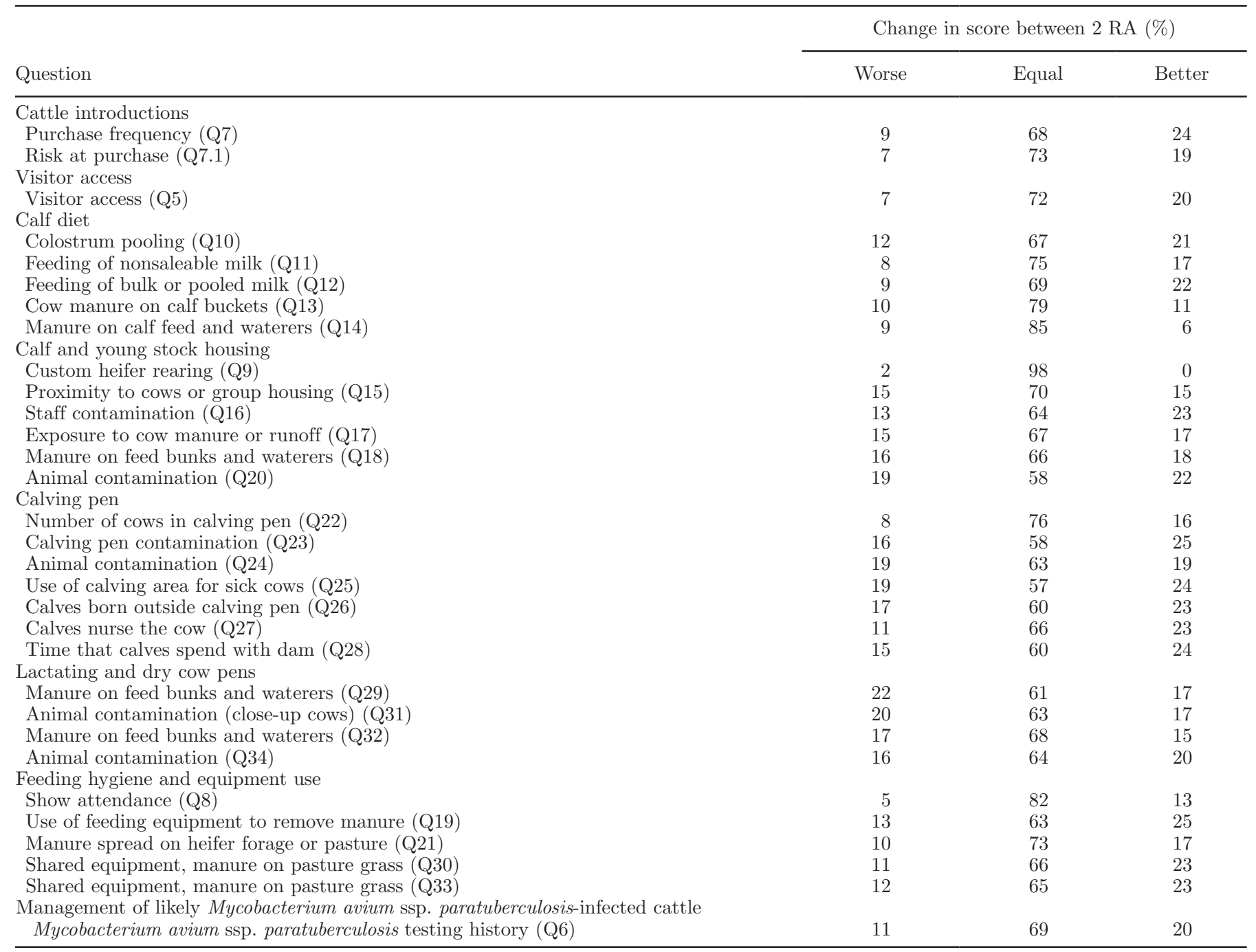


in Pieper et al. (2015). These differences could be explained by differences in farm management between the study locations, but might also be due to differences in RA designs and veterinarian trainings, making veterinarians focus on certain management areas on a farm.

Proposed management improvements in various categories differed among veterinarians, suggesting that veterinarians may have had preferences for specific management practices, which confirms findings of another study (Pieper et al., 2015). However, interobserver variability was only approximated within the present study because management suggestions were not compared between veterinarians conducting MP on the same farms.

A still unaddressed question is whether the implementation of management practices resulted in a reduction of MAP-positive ES and, therefore, a reduction of MAP within-herd prevalence. We refrained from addressing this question because it was assumed that ES were too imprecise to approximate MAP within-herd prevalence, and the study duration of 2 to $4 \mathrm{yr}$ was too short to achieve a detectable within-herd prevalence re- duction, considering that suggested management practices mainly addressed cow-to-calf transmission and ES collection was only done in cow pens. Furthermore, the ES culture protocol improved over the years, resulting in a higher number of positive samples in 2013 than in 2010, which would have biased study results (Wolf et al., 2014a). However, knowledge on effectiveness of various management practices for control of MAP is a major knowledge gap which needs to be addressed in future studies.

A limitation of our study was the method of risk factor and management assessment, with some risk factors and management practices assessed by veterinarians (e.g., animal contamination), and others assessed by producers (e.g., number of cows that calve outside the calving pen). Self-reported management can differ from true management, mainly because of misunderstanding the subject, suggesting potential for bias due to producer-assessed management (Sayers et al., 2013). This might especially be important in Alberta, where many dairy farmers are recent immigrants, which makes knowledge of the language a likely constraint.

Table 4. Changes in risk assessment (RA) question scores for individual questions assessed on 233 farms participating in the Alberta Johne's Disease Initiative for at least $2 \mathrm{yr}$

\begin{tabular}{|c|c|c|c|}
\hline Item & \multicolumn{3}{|c|}{ Change in score between 2 RA [n (\%)] } \\
\hline 0 & $804(12)$ & $4,591(69)$ & $1,244(19)$ \\
\hline $1-3$ & $306(13)$ & $1,619(70)$ & $404(17)$ \\
\hline $4-6$ & $220(16)$ & $855(63)$ & $291(21)$ \\
\hline \multicolumn{4}{|l|}{ Proposed management change } \\
\hline \multicolumn{4}{|l|}{ RA section } \\
\hline Cattle introductions & $54(8)$ & $480(71)$ & $146(21)$ \\
\hline Visitor access & $25(7)$ & $247(72)$ & $69(20)$ \\
\hline Calf diet & $134(10)$ & $985(73)$ & $239(18)$ \\
\hline Calf and young stock housing & $252(12)$ & $1,497(74)$ & $286(14)$ \\
\hline Calving pen & $358(15)$ & $1,493(63)$ & $523(22)$ \\
\hline Lactating and dry cow pens & $306(18)$ & $1,093(64)$ & $296(17)$ \\
\hline \multicolumn{4}{|l|}{ Year } \\
\hline 4th RA & $33(15)$ & $156(72)$ & $28(13)$ \\
\hline \multicolumn{4}{|l|}{ Mean question score in previous RA } \\
\hline 1st quartile (low risk) & $425(15)$ & $1,958(69)$ & $440(16)$ \\
\hline 2nd quartile & $344(13)$ & $1,838(70)$ & $428(16)$ \\
\hline 3rd quartile & $291(12)$ & $1,717(68)$ & $503(20)$ \\
\hline 4th quartile (high risk) & $280(11)$ & $1,702(66)$ & $594(23)$ \\
\hline \multicolumn{4}{|l|}{ Herd size } \\
\hline$<100$ cows & $355(11)$ & $2,183(70)$ & $594(19)$ \\
\hline 100-199 cows & $750(13)$ & $3,852(68)$ & $1,047(19)$ \\
\hline$>199$ cows & $235(14)$ & $1,180(68)$ & $324(19)$ \\
\hline \multicolumn{4}{|l|}{ Question score in the previous year } \\
\hline Low risk $(<3)$ & $1,152(18)$ & $4,633(73)$ & $539(9)$ \\
\hline High risk $(>2)$ & $188(4)$ & $2,582(62)$ & $1,426(34)$ \\
\hline
\end{tabular}


However, the scores for all questions were recorded by veterinarians who could clarify questions for producers, which likely reduced potential for bias through misunderstanding. Another related concern might be that producers falsely stated that they implemented management practices to achieve progress. This was mitigated by data being collected by herd veterinarians, who are trusted advisors on the farm. Furthermore, producers received a written statement stating that results were treated anonymously by researchers, and no financial rewards were given for improvements in management. In addition, because management improvements were assessed through comparisons between subsequent RA scores instead of through asking whether changes were made, improvement rates were unlikely to have been overestimated.

Because herd size and MAP prevalence did not differ between study participants and nonparticipants (Ritter et al., 2014), the study population was likely representative of the target population. Study results can be generalized to other dairy farm populations because herd sizes and management strategies in freestall herds are likely similar in other Canadian provinces, Europe, and most states in the United States. Adoption rates of best management practices are likely higher in control programs for diseases that more frequently manifest as clinical disease, such as digital dermatitis or mastitis, because associated disease losses are more visible to farmers, and therefore more obvious than losses through MAP. Therefore, results of the current study can be generalized to control programs on dairy farms targeting infectious pathogens with primarily subclinical occurrence.

\section{CONCLUSIONS}

Participation in a management-based MAP-control program resulted in management improvements on most farms. These management improvements were targeted toward weaknesses identified in current management. Farms that were ES MAP-positive were more likely to implement new best management practices than ESnegative farms, which suggests that knowledge of the infection status of a herd is important for management

Table 5. Final multilevel logistic regression model for improvement in the score of a question between 2 consecutive annual Johne's disease risk assessments

\begin{tabular}{|c|c|c|c|c|c|}
\hline Item & Odds ratio & $95 \% \mathrm{CI}$ & $P$-value & $\begin{array}{l}\text { Variance } \\
\text { (SEM) }\end{array}$ & $\%$ Variance \\
\hline $\begin{array}{l}\text { Intercept } \\
\text { Number Mycobacterium avium ssp. paratuberculosis-positive } \\
\text { environmental samples }\end{array}$ & $-2.70^{1}$ & -2.93 to -2.46 & $\begin{array}{r}<0.001 \\
0.029^{2}\end{array}$ & & \\
\hline 0 & Reference & & & & \\
\hline $1-3$ & 0.93 & 0.77 to 1.14 & 0.502 & & \\
\hline $4-6$ & 1.32 & 1.03 to 1.68 & 0.026 & & \\
\hline Yes & 1.37 & 1.64 to 1.61 & $<0.001$ & & \\
\hline RA section & & & $<0.001^{2}$ & & \\
\hline Cattle introductions & Reference & & & & \\
\hline Visitor access & 1.28 & 0.90 to 1.82 & 0.167 & & \\
\hline Calf diet & 1.49 & 1.16 to 1.93 & 0.002 & & \\
\hline Young stock housing & 1.48 & 1.16 to 1.89 & 0.002 & & \\
\hline Calving pen & 2.22 & 1.76 to 2.78 & $<0.001$ & & \\
\hline 3rd RA & 0.63 & 0.54 to 0.73 & $<0.001$ & & \\
\hline 4th RA & 0.55 & 0.39 to 0.93 & 0.025 & & \\
\hline Mean question score in previous RA & \multicolumn{2}{|c|}{ Not significant } & $(0.473)^{2}$ & & \\
\hline Herd size (no. of cows) & \multirow{2}{*}{\multicolumn{2}{|c|}{ Not significant }} & $(0.149)^{2}$ & & \\
\hline Score in that question in the previous year & & & $<0.001^{2}$ & & \\
\hline Low risk $(<3)$ & Reference & & & & \\
\hline High risk $(>2)$ & 7.21 & 6.33 to 8.20 & $<0.001$ & & \\
\hline Random effects & & & & & \\
\hline Veterinarian & & & & $0.12(0.06)$ & 4 \\
\hline Herd & & & & $0.29(0.05)$ & 8 \\
\hline Observation & & & & - & 88 \\
\hline
\end{tabular}

${ }^{1}$ Variable describes the log odds for management improvement in the baseline group.

${ }^{2}$ Overall Wald $P$-value for the independent variable. 
decisions. Furthermore, management improvements decreased over years of participation, suggesting that it became increasingly difficult to make management improvements, based on the knowledge gained by conducting the same RA over several years.

\section{ACKNOWLEDGMENTS}

The authors thank the farmers and veterinarians for participation in the study. We also thank Alberta Milk (Edmonton, Canada) personnel for promotion and assistance in administration. Funding was provided by Alberta Milk, the Alberta Livestock and Meat Agency (ALMA; Edmonton, Canada), and the Canadian Agricultural Adaptation Program (CAAP; Ottawa, Canada). We also thank John Kastelic (University of Calgary) for editing the manuscript.

\section{REFERENCES}

Atreya, R., M. Bülte, G.-F. Gerlach, R. Goethe, M. W. Hornef, H. Köhler, J. Meens, P. Möbius, E. Roeb, and S. Weiss. 2014. Facts, myths and hypotheses on the zoonotic nature of Mycobacterium avium subspecies paratuberculosis. Int. J. Med. Microbiol. 304:858867.

Barkema, H. W., J. W. Hesselink, S. L. B. McKenna, A. Benedictus, and H. Groenendaal. 2010. Global prevalence and economics of infection with Mycobacterium avium ssp. paratuberculosis in ruminants. Pages 10-21 in Paratuberculosis, Organism, Disease, Control. M. A. Behr and D. M. Collins, ed. CABI, Wallingford, UK.

Bergevoet, R. H. M., C. J. M. Ondersteijn, H. W. Saatkamp, C. M. J. van Woerkum, and R. B. M. Huirne. 2004. Entrepreneurial behaviour of dutch dairy farmers under a milk quota system: goals, objectives and attitudes. Agric. Syst. 80:1-21.

Dohoo, I., M. Wayne, and S. Henrik. 2003. Introduction to clustered data. Pages 459-472 in Veterinary Epidemiologic Research. M. S. McPike, ed. Atlantic Veterinary College, Charlottetown, Canada.

Dohoo, I. R., S. W. Martin, and H. Stryhn. 2009. Mixed models for discrete data. Pages 579-606 in Veterinary Epidemiologic Research. M. S. McPike, ed. Atlantic Veterinary College, Charlottetown, Canada.

Edwards-Jones, G. 2006. Modelling farmer decision-making: Concepts, progress and challenges. Anim. Sci. 82:783-790.

Forde, T., J. De Buck, B. Elkin, S. Kutz, F. van der Meer, and K. Orsel. 2013. Contrasting results of culture-dependent and molecular analyses of Mycobacterium avium ssp. paratuberculosis from wood bison. Appl. Environ. Microbiol. 79:4448-4454.

Garry, F. 2011. Control of paratuberculosis in dairy herds. Vet. Clin. North Am. Food Anim. Pract. 27:599-607.

McKenna, S. L. B., G. P. Keefe, A. Tiwari, J. A. VanLeeuwen, and H. W. Barkema. 2006. Johne's disease in Canada Part II: Disease impacts, risk factors and control programs for dairy producers. Can. Vet. J. 47:1089-1099.

Mortier, R. A. R., H. W. Barkema, M. E. Negron, K. Orsel, R. Wolf, and J. De Buck. 2014a. Antibody response early after experimen- tal infection with Mycobacterium avium subspecies paratuberculosis in dairy calves. J. Dairy Sci. 97:5558-5565.

Mortier, R. A. R., H. W. Barkema, K. Orsel, R. Wolf, and J. De Buck. 2014b. Shedding patterns of dairy calves experimentally infected with Mycobacterium avium subspecies paratuberculosis. Vet. Res. 45:71-80.

Mueller, R. A. E., and H. G. P. Jansen. 1988. Farmer and farm concepts in measuring adoption lags. J. Agric. Econ. 39:121-124.

Nielsen, S. S., and N. Toft. 2008. Ante mortem diagnosis of paratuberculosis: A review of accuracies of ELISA, interferon- $\gamma$ assay and faecal culture techniques. Vet. Microbiol. 129:217-235.

Pieper, L., T. J. DeVries, U. S. Sorge, A. Godkin, K. J. Hand, N. R. Perkins, J. Imada, and D. F. Kelton. 2015. Variability in risk assessment and management plan (RAMP) scores completed as part of the Ontario Johne's education and management assistance program (2010-2013). J. Dairy Sci. 98:2419-2426.

Raizman, E. A., S. J. Wells, S. M. Godden, J. Fetrow, K. Friendshuh, and J. Michael Oakes. 2006. Characterization of Minnesota dairy herds participating in a Johne's disease control program and evaluation of the program risk assessment tool. Prev. Vet. Med. $75: 22-33$

Ritter, C., R. Wolf, J. Flaig, C. Pickel, M. Slomp, B. S. Mason, D. Kelton, J. Jansen, J. De Buck, and H. W. Barkema. 2014. Participation in the Alberta Johne's Disease Initiative is not associated with MAP herd prevalence, herd size or enrolment in a DHI program. Page 112 in Proc. 12th Intern. Colloq. on Paratuberculosis (ICP), Parma, Italy. International Association for Paratuberculosis, Parma, Italy.

Sayers, R. G., G. P. Sayers, J. F. Mee, M. Good, M. L. Bermingham, J. Grant, and P. G. Dillon. 2013. Implementing biosecurity measures on dairy farms in Ireland. Vet. J. 197:259-267.

Sorge, U. S., K. Lissemore, A. Godkin, J. Jansen, S. Hendrick, S. Wells, and D. F. Kelton. 2011. Changes in management practices and apparent prevalence on Canadian dairy farms participating in a voluntary risk assessment-based Johne's disease control program. J. Dairy Sci. 94:5227-5237.

Sweeney, R. W. 2011. Pathogenesis of paratuberculosis. Vet. Clin. North Am. Food Anim. Pract. 27:537-546.

USDA. 2003. Handbook for Veterinarians and Dairy Producers. A guide for Johne's disease risk assessment and managment plans for dairy herds. Accessed February 3, 2015. http://www.nd.gov/ ndda/files/resource/DairyRiskAssessment1stYear2011_0.pdf.

Vigre, H., I. R. Dohoo, H. Stryhn, and M. E. Busch. 2004. Intra-unit correlations in seroconversion to Actinobacillus pleuropneumoniae and Mycoplasma hyopneumoniae at different levels in Danish multi-site pig production facilities. Prev. Vet. Med. 63:9-28.

Wells, S. J., W. L. Hartmann, and P. L. Anderson. 2008. Evaluation of progress made by dairy and beef herds enrolled in the Minnesota Johne's disease control program. J. Am. Vet. Med. Assoc. 233:1920-1926.

Whitlock, R. H., and C. Buergelt. 1996. Preclinical and clinical manifestations of paratuberculosis (including pathology). Vet. Clin. North Am. Food Anim. Pract. 12:345-356.

Wolf, R., H. W. Barkema, J. De Buck, M. Slomp, J. Flaig, D. Haupstein, C. Pickel, and K. Orsel. 2014a. High herd-level prevalence of Mycobacterium avium subspecies paratuberculosis in Western Canadian dairy farms, based on environmental sampling. J. Dairy Sci. 97:6250-6259.

Wolf, R., F. Clement, H. W. Barkema, and K. Orsel. 2014b. Economic evaluation of participation in a voluntary Johne's disease prevention and control program from a farmer's perspective- The Alberta Johne's Disease Initiative. J. Dairy Sci. 97:2822-2834. 


\section{APPENDIX}

Table A1. Prevalence of risk factors on farms participating in the Alberta Johne's Disease (JD) Initiative, stratified by the year of participation

Year of participation

Item

$1 \quad 2 \quad 3 \quad 4$

General section

Q5. What access do farm visitors have?

No restrictions

Restrictions to mature cattle

Restrictions to preweaned cattle

Restricted access or required to wear special clothing

Q6. JD history?

Yes, JD has been observed in the herd

Do not know

JD never observed; no testing done

JD never observed; testing in past $5 \mathrm{yr}$ with negative results

Q7. Did you purchase any animals, including bulls, in last 5 yr?

Yes, from multiple herds at public auctions

Yes, from auctions with known contributors

Yes, but only 1 or 2 animals from a single herd

Yes, from JD Herd Status Program ${ }^{1}$ farms

No purchases

Q7.1. What precautions were taken?

No precautions

Seller indicated no JD in the herd, but had never tested

Purchased animals were tested before delivery

Purchased animals came from low-risk herds (JD Herd Status Program)

No purchases

Q8. Show attendance; equipment sharing

Yes, herd members attend shows or hauled in shared vehicles

Yes, pens are cleaned by custom manure removal operations

Yes, shows are only attended with herds with lower risk for Mycobacterium avium ssp. paratuberculosis

No show attendance, no shared equipment

Preweaned heifers

Q9. Are any calves raised on custom heifer-rearing operations?

Yes, the rearing operation raises heifers from multiple herds

Yes, but the rearing operation raises only heifers from my herd

No, all heifers are raised on farm

Q10. What is the source of colostrum?

Pooled colostrum from $>1$ cow

Some calves get colostrum from a cow other than their dam

Calves are only given their dam's colostrum

Calves are only given pasteurized colostrum or colostrum replacer

Q11. How often is nonsaleable milk fed to calves?

Nonsaleable milk is always (weekly) fed

Nonsaleable milk is often (once or twice a month) fed

Nonsaleable milk is rarely (once or twice a year) fed

Nonsaleable milk is never fed

Q12. What are the sources of liquid diet fed to calves?

Bulk or pooled milk

Milk from individual cows

Pasteurized milk or milk replacer for $<2 \mathrm{yr}$

Pasteurized milk or milk replacer for $>2 \mathrm{yr}$

Q13. Is there any cow manure on milk feeding utensils?

Extensive manure contamination

Some manure contamination

Traces of manure, but utensils washed at least weekly

No manure, utensils washed daily

Q14. Is there any cow manure in water buckets and feed bunks?

Extensive manure contamination

Manure is clearly visible in calf feeders or water buckets

A scant amount of manure is visible

All calf feed and water containers are clean

Q15. How are calves housed?

Close proximity to cows

Group pens until weaning

Individual pens with contact through partitions

Individual pens without contact

\begin{tabular}{|c|c|c|c|}
\hline 234 & 115 & 41 & 0 \\
\hline 28 & 22 & 9 & 0 \\
\hline 26 & 28 & 13 & 1 \\
\hline 82 & 67 & 36 & 6 \\
\hline 109 & 71 & 31 & 0 \\
\hline 99 & 34 & 27 & 2 \\
\hline 97 & 42 & 10 & 1 \\
\hline 65 & 86 & 31 & 4 \\
\hline 180 & 96 & 30 & 2 \\
\hline 90 & 53 & 38 & 4 \\
\hline 1 & 9 & 5 & 0 \\
\hline 52 & 38 & 12 & 0 \\
\hline 272 & 143 & 50 & 5 \\
\hline 31 & 25 & 16 & 0 \\
\hline 13 & 9 & 8 & 0 \\
\hline 5 & 19 & 13 & 2 \\
\hline 49 & 37 & 12 & 0 \\
\hline 60 & 27 & 9 & 1 \\
\hline 33 & 20 & 9 & 1 \\
\hline 9 & 3 & 2 & 0 \\
\hline 268 & 183 & 79 & 5 \\
\hline 11 & 4 & 5 & 1 \\
\hline 2 & 4 & 2 & 0 \\
\hline 357 & 225 & 92 & 6 \\
\hline 37 & 13 & 4 & 0 \\
\hline 176 & 95 & 45 & 2 \\
\hline 124 & 92 & 36 & 4 \\
\hline 33 & 33 & 14 & 1 \\
\hline 178 & 94 & 27 & 1 \\
\hline 47 & 28 & 15 & 0 \\
\hline 24 & 12 & 11 & 0 \\
\hline 121 & 99 & 46 & 6 \\
\hline 208 & 103 & 35 & 2 \\
\hline 41 & 32 & 12 & 0 \\
\hline 34 & 33 & 12 & 2 \\
\hline 87 & 65 & 40 & 3 \\
\hline 2 & 1 & 0 & 0 \\
\hline 20 & 5 & 4 & 1 \\
\hline 108 & 69 & 25 & 2 \\
\hline 240 & 158 & 70 & 4 \\
\hline 3 & 0 & 0 & 0 \\
\hline 12 & 3 & 4 & 1 \\
\hline 83 & 44 & 20 & 1 \\
\hline 272 & 186 & 75 & 5 \\
\hline 14 & 9 & 1 & 0 \\
\hline 72 & 38 & 20 & 3 \\
\hline 107 & 61 & 24 & 1 \\
\hline 177 & 125 & 54 & 3 \\
\hline
\end{tabular}


Table A1 (Continued). Prevalence of risk factors on farms participating in the Alberta Johne's Disease (JD) Initiative, stratified by the year of participation

\begin{tabular}{|c|c|c|c|c|}
\hline Item & \multicolumn{4}{|c|}{ Year of participation } \\
\hline \multicolumn{5}{|l|}{ Q16. Staff hygiene routine when entering calf barn } \\
\hline Staff never clean boots or change coveralls & 107 & 35 & 9 & 0 \\
\hline Staff sometimes clean boots and change coveralls & 110 & 68 & 28 & 2 \\
\hline Staff always clean boots and sometimes change coveralls & 132 & 107 & 48 & 4 \\
\hline Staff always clean boots and change coveralls & 21 & 23 & 14 & 1 \\
\hline Heifers share pens or pastures with cows & 123 & 70 & 29 & 1 \\
\hline Heifers are housed near cows, exposure to runoff & 150 & 103 & 47 & 1 \\
\hline Heifers housed near cows, no exposure to runoff & 48 & 22 & 11 & 0 \\
\hline Heifers never housed near cows, no exposure to runoff & 49 & 38 & 12 & 2 \\
\hline \multicolumn{5}{|l|}{ Q18. Manure contamination of feed bunks and water troughs } \\
\hline Manure build-up in housing, contaminated feed bunks and water troughs & 14 & 2 & 0 & 0 \\
\hline Manure clearly visible in feed bunks and water troughs & 97 & 49 & 17 & 2 \\
\hline Feeding equipment not used for manure, but cow left over feed fed to heifers $>1$ yr of age & 54 & 42 & 18 & 2 \\
\hline Feeding equipment is not used for manure, left over feed is never fed to heifers & 109 & 92 & 51 & 2 \\
\hline \multicolumn{5}{|l|}{ Q20. To what degree is manure contamination evident on heifers? } \\
\hline Manure is present above hocks or knees and on flanks & 40 & 12 & 5 & 0 \\
\hline Manure is present on hocks or knees or on flanks & 161 & 90 & 47 & 6 \\
\hline Manure is present up to dewclaws & 135 & 104 & 40 & 1 \\
\hline No visible manure on animals & 33 & 27 & 7 & 0 \\
\hline \multicolumn{5}{|l|}{ Q21. Manure spread on heifer forage or pasture used the same year } \\
\hline Manure is spread on pastures where heifers graze & 36 & 12 & 4 & 0 \\
\hline Manure is spread on land next to heifer pastures & 21 & 9 & 2 & 0 \\
\hline Manure is spread on forage land used to feed heifers & 131 & 74 & 33 & 1 \\
\hline Manure is never spread on land used for heifers & 181 & 138 & 60 & 6 \\
\hline \multicolumn{5}{|l|}{ Calving pen } \\
\hline \multicolumn{5}{|l|}{ Q22. How many cows are in a calving pen at a time? } \\
\hline \multicolumn{5}{|l|}{ Q24. To what degree is manure contamination evident on cows? } \\
\hline Manure present above hocks and on teats or udders & 17 & 3 & 3 & 0 \\
\hline Manure present up to hocks or on teats or udders & 100 & 56 & 23 & 5 \\
\hline Manure present above dewclaws, but not on teats or udders & 209 & 145 & 65 & 2 \\
\hline No visible manure, udder hair is clipped and teats are washed & 44 & 29 & 8 & 0 \\
\hline \multicolumn{5}{|l|}{ Q25. Use of calving area for sick cows } \\
\hline $\begin{array}{l}\text { Frequent use of calving area by noncalving cows or known Mycobacterium avium ssp. } \\
\text { paratuberculosis-positive cows }\end{array}$ & 80 & 46 & 12 & 0 \\
\hline Occasional use of calving area by noncalving cows & 68 & 44 & 19 & 0 \\
\hline Rare use of calving area by noncalving cows & 106 & 62 & 32 & 3 \\
\hline Calving area is never used by noncalving cows & 116 & 81 & 36 & 4 \\
\hline \multicolumn{5}{|l|}{ Q26. Calves born outside the calving area in the past year } \\
\hline$>10 \%$ & 80 & 40 & 16 & 0 \\
\hline $6-10 \%$ & 33 & 25 & 9 & 0 \\
\hline $1-5 \%$ & 173 & 108 & 48 & 4 \\
\hline Never & 84 & 60 & 26 & 3 \\
\hline Q27. What percentage of calves nurse their dam? & & & & \\
\hline$>50 \%$ nurse their dam, are left $>4 \mathrm{~h}$ & 93 & 36 & 12 & 0 \\
\hline $10-50 \%$ nurse their dam & 96 & 63 & 24 & 0 \\
\hline$<10 \%$ nurse their dam & 155 & 112 & 57 & 6 \\
\hline None & 26 & 22 & 6 & 1 \\
\hline
\end{tabular}


Table A1 (Continued). Prevalence of risk factors on farms participating in the Alberta Johne's Disease (JD) Initiative, stratified by the year of participation

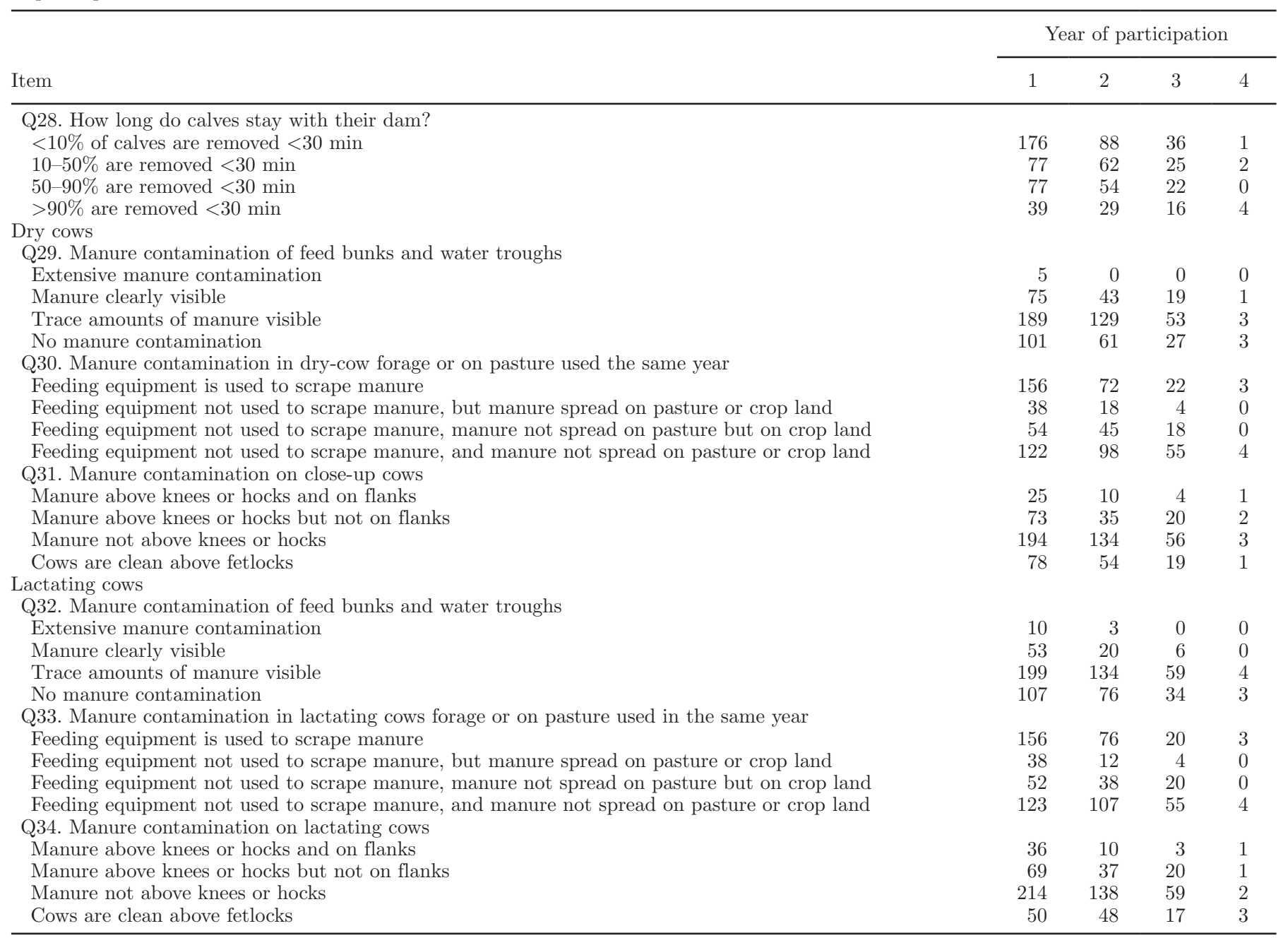

${ }^{1}$ JD Herd Status Program: This is a voluntary program in which participating farms can be certified as farms with a low risk for Mycobacterium avium ssp. paratuberculosis infection through repeated testing. 